\title{
Synthesis of Silica Nanoparticles by Sol-Gel: Size-Dependent Properties, Surface Modification, and Applications in Silica-Polymer Nanocomposites-A Review
}

\author{
Ismail Ab Rahman' and Vejayakumaran Padavettan ${ }^{2}$ \\ ${ }^{1}$ School of Dental Sciences, Universiti Sains Malaysia, Health Campus, Kelantan, 16150 Kubang Kerian, Malaysia \\ ${ }^{2}$ Assembly Technology Development Malaysia, Intel Technology Sdn Bhd, Kulim Hi-Tech Park, Kedah, 09000 Kulim, Malaysia
}

Correspondence should be addressed to Ismail Ab Rahman, arismail@usm.my

Received 10 January 2012; Accepted 27 February 2012

Academic Editor: Sevan P. Davtyan

Copyright (C) 2012 I. A. Rahman and V. Padavettan. This is an open access article distributed under the Creative Commons Attribution License, which permits unrestricted use, distribution, and reproduction in any medium, provided the original work is properly cited.

\begin{abstract}
Application of silica nanoparticles as fillers in the preparation of nanocomposite of polymers has drawn much attention, due to the increased demand for new materials with improved thermal, mechanical, physical, and chemical properties. Recent developments in the synthesis of monodispersed, narrow-size distribution of nanoparticles by sol-gel method provide significant boost to development of silica-polymer nanocomposites. This paper is written by emphasizing on the synthesis of silica nanoparticles, characterization on size-dependent properties, and surface modification for the preparation of homogeneous nanocomposites, generally by sol-gel technique. The effect of nanosilica on the properties of various types of silica-polymer composites is also summarized.
\end{abstract}

\section{Introduction}

Nanotechnology is rapidly sweeping through all vital fields of science and technology such as electronic, aerospace, defense, medical, and dental. This involves in design, synthesis, characterization, and application of material and devices on the nanometer scale. At the nanoscale, physical, chemical, and biological properties differ from the properties of individual atoms and molecules of bulk matter. Therefore, it provides opportunity to develop new classes of advanced materials which meet the demands from high-tech applications [1-5].

Development of ceramic nanoparticles with improved properties has been studied with much success in several areas such as synthesis and surface science. Examples of ceramic are silica, alumina, titania, zirconia, silicon nitride, silicon carbide, and so forth. Advancement in nanotechnology has led to the production of nanosized silica, $\mathrm{SiO}_{2}$, which has been widely used as filler in engineering composite. The silica particles extracted from natural resources contains metal impurities and not favorable for advanced scientific and industrial applications. Thus, focus is given to synthetic silica (colloidal silica, silica gels, pyrogenic silica, and precipitated silica), which is pure and produced mostly in amorphous powder forms compared to natural mineral silica (quartz, tridymite, cristobalite) which are in crystalline forms [6]. As shown in Figure 1, various methods that have been used to obtain silica particles can be categorized into two main approaches: top-down and bottom-up [2, 7]. Top-down is characterized by reducing the dimension of the original size by utilizing special size reduction techniques (physical approach). Bottom-up or chemical approach involves a common route used to produce silica nanoparticles from atomic or molecular scale. Some of the widely used methods to synthesize silica nanoparticles are sol-gel process, reverse microemulsion, and flame synthesis. The sol-gel process is widely used to produce pure silica particles due to its ability to control the particle size, size distribution and morphology through systematic monitoring of reaction parameters.

This paper will focus on the aspect of synthesis, sizedependent properties, and surface modification of nanosilica toward preparation of nanocomposites, generally by sol-gel. 


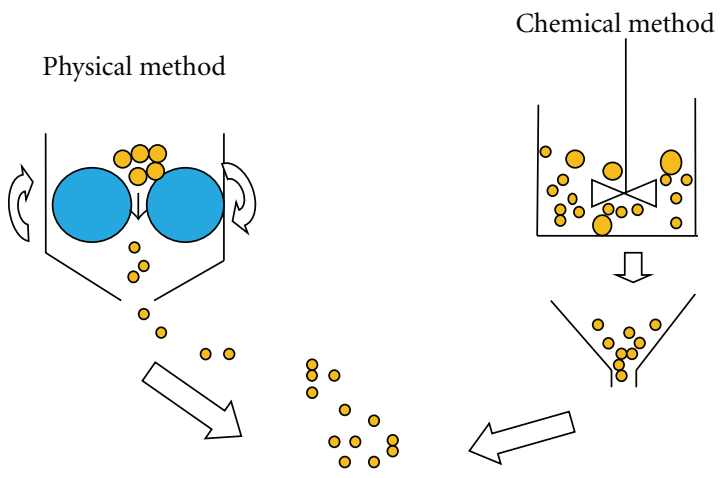

Figure 1: Physical and chemical approaches to produce nanomaterials.

Although numerous works on the preparations of silicapolymer nanocomposites are reported in the literatures, the focus on the above aspect is lacking.

\section{Synthesis of Nanosilica}

Some of the methods used to synthesize silica nanoparticles are reverse microemulsion and flame synthesis and widely utilized sol-gel. In reverse microemulsion, the surfactants molecules dissolved in organic solvents forms spherical micelles. In the presence of water, the polar head groups organize themselves to form microcavities containing water, which is often called as reverse micelles. The method was recently reviewed by Tan et al. [8]. In synthesis of silica nanoparticles, the nanoparticles can be grown inside the microcavities by carefully controlling the addition of silicon alkoxides and catalyst into the medium containing reverse micelles. The major drawbacks of the reverse microemulsion approach are high cost and difficulties in removal of surfactants in the final products. However, the method was successfully applied for the coating of nanoparticles with different functional groups for various applications $[9,10]$.

Silica nanoparticles can also be produced through high temperature flame decomposition of metal-organic precursors. This process is also referred to as chemical vapor condensation (CVC) [11]. In a typical CVC process, silica nanoparticles are produced by reacting silicon tetrachloride, $\mathrm{SiCl}_{4}$ with hydrogen and oxygen [6]. Difficulty in controlling the particle size, morphology, and phase composition is the main disadvantage of the flame synthesis [2]. Nevertheless, this is the prominent method that has been used to commercially produce silica nanoparticles in powder form.

\section{Synthesis of Nanosilica Particles by Sol-Gel Process}

For decay, the sol-gel process is widely applied to produce silica, glass, and ceramic materials due to its ability to form pure and homogenous products at mild conditions. The process involves hydrolysis and condensation of metal alkoxides $\left(\mathrm{Si}(\mathrm{OR})_{4}\right)$ such as tetraethylorthosilicate (TEOS, $\left.\mathrm{Si}\left(\mathrm{OC}_{2} \mathrm{H}_{5}\right)_{4}\right)$ or inorganic salts such as sodium silicate $\left(\mathrm{Na}_{2} \mathrm{SiO}_{3}\right)$ in the presence of mineral acid (e.g., $\left.\mathrm{HCl}\right)$ or base

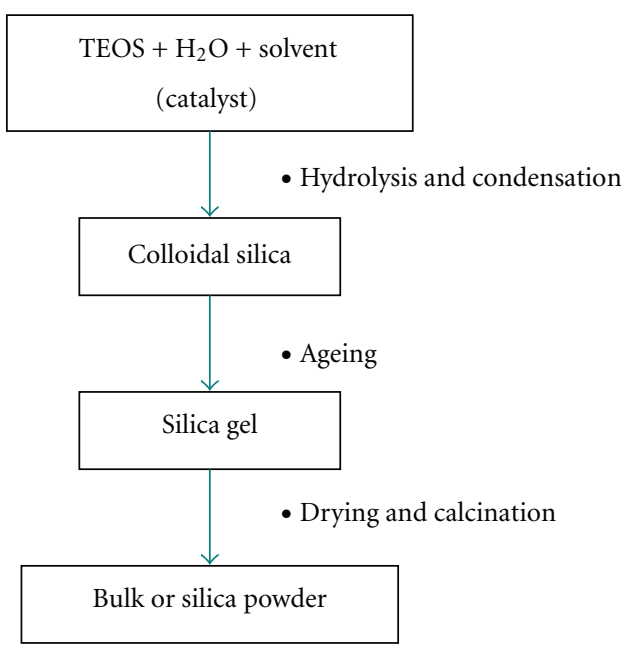

FIGURE 2: Flow chart of a typical sol-gel process.

(e.g., $\mathrm{NH}_{3}$ ) as catalyst [12-14]. A general flow chart for solgel process which leads to the production silica using silicon alkoxides $\left(\mathrm{Si}(\mathrm{OR})_{4}\right)$ is shown in Figure 2.

The general reactions of TEOS that leads to the formation of silica particles in the sol-gel process can be written as [13$18]$ :

$$
\begin{aligned}
& \mathrm{Si}\left(\mathrm{OC}_{2} \mathrm{H}_{5}\right)_{4}+\mathrm{H}_{2} \mathrm{O} \\
& \stackrel{\text { hydrolysis }}{\longrightarrow} \mathrm{Si}\left(\mathrm{OC}_{2} \mathrm{H}_{5}\right)_{3} \mathrm{OH}+\mathrm{C}_{2} \mathrm{H}_{5} \mathrm{OH} \\
& \equiv \mathrm{Si}-\mathrm{O}-\mathrm{H}+\mathrm{H}-\mathrm{O}-\mathrm{Si} \equiv \\
& \stackrel{\text { water condensation }}{\longrightarrow} \equiv \mathrm{Si}-\mathrm{O}-\mathrm{Si} \equiv+\mathrm{H}_{2} \mathrm{O} \\
& \equiv \mathrm{Si}-\mathrm{OC}_{2} \mathrm{H}_{5}+\mathrm{H}-\mathrm{O}-\mathrm{Si} \equiv \\
& \stackrel{\text { alcohol condensation }}{\longrightarrow} \equiv \mathrm{Si}-\mathrm{O}-\mathrm{Si} \equiv+\mathrm{C}_{2} \mathrm{H}_{5} \mathrm{OH} .
\end{aligned}
$$

The hydrolysis of TEOS molecules forms silanol groups. The condensation/polymerization between the silanol groups or between silanol groups and ethoxy groups creates siloxane bridges $(\mathrm{Si}-\mathrm{O}-\mathrm{Si})$ that form entire silica structure.

The formation of silica particles can be divided into two stages: nucleation and growth. Two models, monomer 


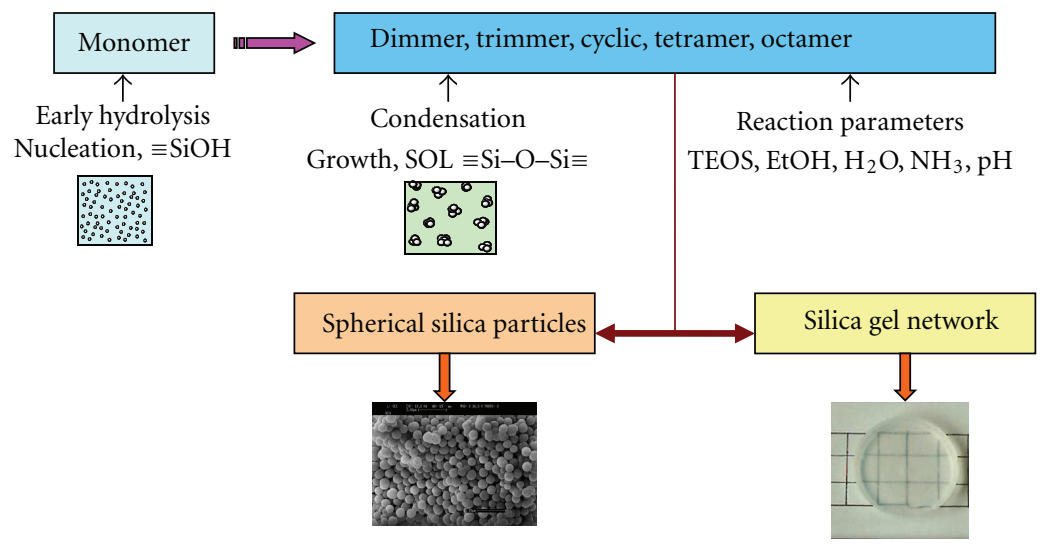

FiguRE 3: Schematic silica formation by sol-gel process.

addition [17, 18] and controlled aggregation [15, 19], have been proposed to describe the growth mechanism of silica. The monomer addition model describes that, after an initial burst of nucleation, the particle growth occurs through the addition of hydrolyzed monomers, the (primary) particle surface. By contrast, the aggregation model elaborates that the nucleation occurs continuously throughout the reaction and the resulting nuclei (primary particles) will aggregate together to form dimmer, trimmer, and larger particles (secondary particles). Both models lead to the formation of either spherical or gel network depending on the reaction conditions as shown in Figure 3.

Many attempts were made by several researchers [1922] to determine the size of the primary particles, using various techniques as tabulated in Table 1. Through SAXS, Green et al. [22] reported that the size of primary particles was $10.3 \mathrm{~nm}$ (in methanol) or $20.7 \mathrm{~nm}$ (in ethanol). Later, Rahman et al. [23] produced a homogeneous and stable silica nanoparticles with mean particles size of $7.1 \pm 1.9 \mathrm{~nm}$ (in ethanol).

A pioneer work on the synthesis of spherical and monodispersed silica particles was reported by Stöber et al. [14]. Silica particles with the size ranging from 5 to $2000 \mathrm{~nm}$ from aqueous alcohol solutions of silica alkoxides in presence of ammonia as catalyst (basic condition) have been produced. Following that many contemporary research works describing the synthesis of nanosilica particles are indeed evolved from the Stöber method. The main advantage of Stöber method is the ability to form monodispersed spherical silica particles compared to the acid-catalyzed systems which usually result gel structures.

3.1. Optimization of Reaction Conditions . An optimized synthesis condition is a combination of optimal values of each reaction parameter of sol-gel method that could produce smallest, homogenous, and monodispersed silica nanoparticles. In principle, smaller nanoparticles are obtained by controlling (slowing down) the rate of polycondensation reactions through manipulation of reaction parameters [19, 24]. Most of the works agreed that the particle size increased with increase in ammonia concentrations [19-25]. Figure 4
TABLE 1: Size of the primary particles reported in the literature.

\begin{tabular}{lcc}
\hline Source & $\begin{array}{c}\text { Primary particle size } \\
(\mathrm{nm})\end{array}$ & Method $^{\mathrm{a}}$ \\
\hline Bogush and Zukoski [19] & $2-4$ & Prediction $^{\mathrm{b}}$ \\
Bailey and Mecartney [20] & 20 & cryo-TEM \\
Lee et al. [21] & $10-20$ & Prediction $^{\mathrm{b}}$ \\
Green et al. [22] & $10.3^{\mathrm{c}}$ or $20.7^{\mathrm{d}}$ & SAXS \\
Rahman et al. [23] & $7^{\mathrm{d}}$ & TEM \\
\hline
\end{tabular}

${ }^{a}$ Refers to diameter (d); ${ }^{b}$ Prediction based on controlled aggregation model; ${ }^{c}$ in methanol, ${ }^{d}$ in ethanol. Calculated using the formula $\mathrm{d}=2 \times R_{g} \times$ $(5 / 3)^{0.5}[22]$.

shows different size of silica obtained by controlling reaction parameters.

The addition of small amount of anion electrolyte additives (ammonium salts of $\mathrm{Br}, \mathrm{I}$, and $\mathrm{Cl}$ ) produced monodispersed silica particles $\sim 20 \mathrm{~nm}$ to $\sim 34 \mathrm{~nm}$ [26] depending on the anions used. The phenomena were explained by conductivity profile during the process as alternative to normally using zeta potential. It was found that all anions were able to reduce the particles size by $73-78 \%$, among them, $\mathrm{Br}$ and $\mathrm{I}^{-}$have the highest effect while $\mathrm{Cl}^{-}$has the least effect. The synthesized silica powder was free from cation impurities.

By fixing concentration of reactants and temperature, the particle size and particle distribution of silica nanoparticle were highly dependent on mixing modes [27]. Mode-A has produced monodispersed powder with average particles size of $\sim 10 \mathrm{~nm}$. The use of freeze dryer has further improved the quality of powder (Figure 5).

In continuing attempts to reduce the size of nanosilica by researchers, a homogeneous, highly dispersed, and stable silica nanoparticle of $\sim 7.1 \mathrm{~nm}$ in the primary size range was reported by Rahman et al. [23] at the optimum conditions of sol-gel process, under the influence of low frequency ultrasound. The optimized technique developed is simple and reproducible, affording a high yield of $\sim 75 \%$ of nanometer silica in a primary size range.

It is obvious that the optimum reaction conditions for a particular system can be systematically set in order to 


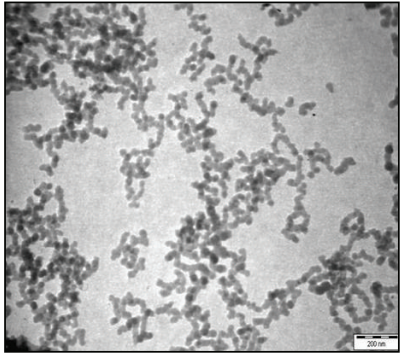

(a)

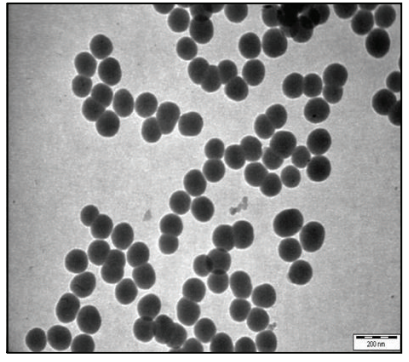

(b)

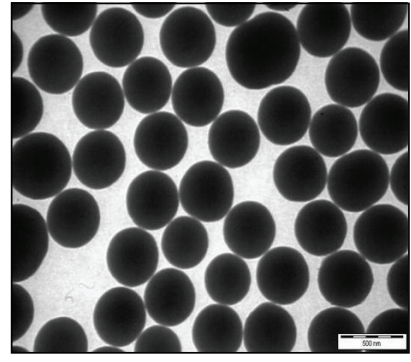

(c)

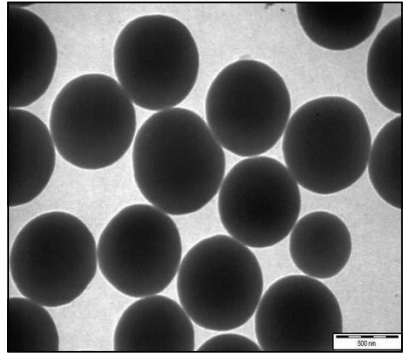

(d)

FIGURE 4: Different size of silica obtained by controlling reaction parameters: (a) 21 nm, (b) $\sim 131 \mathrm{~nm}$, (c) 369 nm, (d) 565 nm.

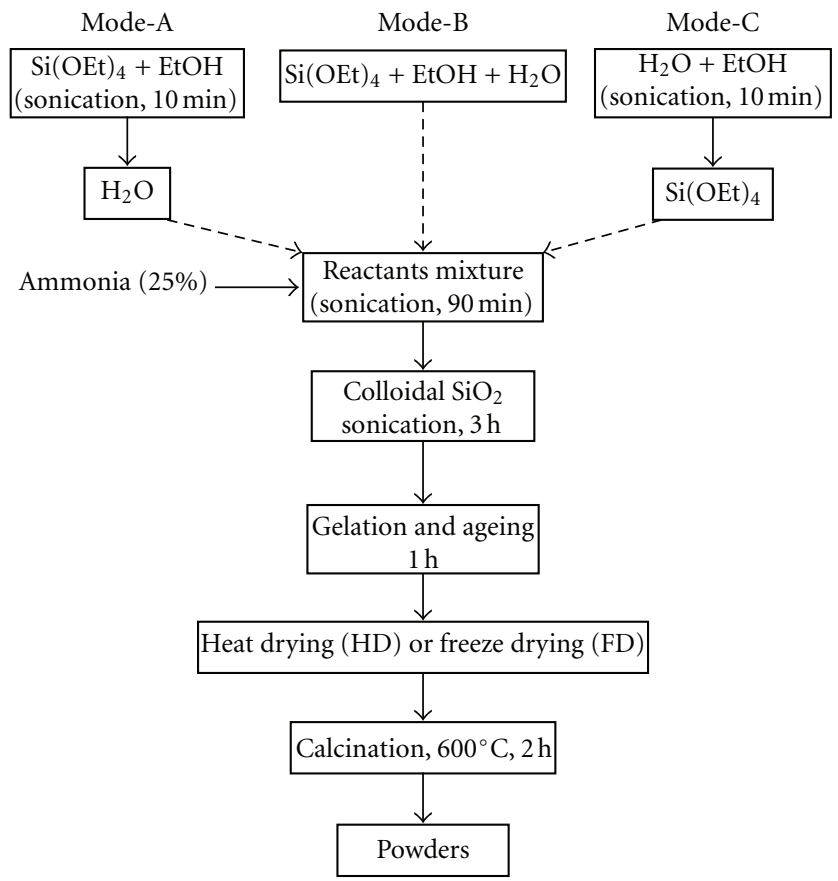

FIGURE 5: Flow chart for nanosilica preparation by different mixing modes [27].

produce a desired particles size and morphology of silica particles.

3.2. Drying and Agglomeration Phenomena. Drying is a simple process which involves fluid to solid transition leading to the formation of solid materials. Yet it is an important step towards producing powdered silica nanoparticles. Works on the drying of silica gels can be found in various review papers and books $[6,13,16]$. Supercritical drying, freeze drying, spray drying, and thermal drying are some of the common techniques used to produce particulate solid materials from the liquid phase. Collision and coalescence of the nanoparticles are the main factors that govern the extent of agglomeration in a nanoparticles powder system. Also, the intense ageing process that occurs during the drying of sol can lead to complex agglomeration behavior arising from polycondensation reactions [13]. In addition, the polycondensation reactions between the silanol groups have been reported to increase in presence of water and catalyst $[13,16]$. Figure 6 illustrates the effect of drying conditions on the morphology of the silica nanoparticles.

A careful controlled drying process leads to the formation of well-dispersed particles, whereas drying in the presence of water can result in agglomeration phenomena. Production of highly dispersed nanoparticles powder is still a challenge owing to the fact that these particles were highly sensitive to the processing conditions. In preparation of silicapolymer nanocomposite, the presence of agglomerates can significantly reduce the silica loading, resulting in reduced thermochemical properties. However, works on controlling the agglomeration of nanosilica via effective drying process are lacking. Thus, this paper shows that it is important to effectively discard water from the colloidal system to reduce the agglomeration level during the drying process.

The strength of agglomerates was largely depending on the solubility of the nanoparticles [28]. The strength of water-dispersed agglomerated was found almost three times higher compared to the ethanol dispersed agglomerates due 


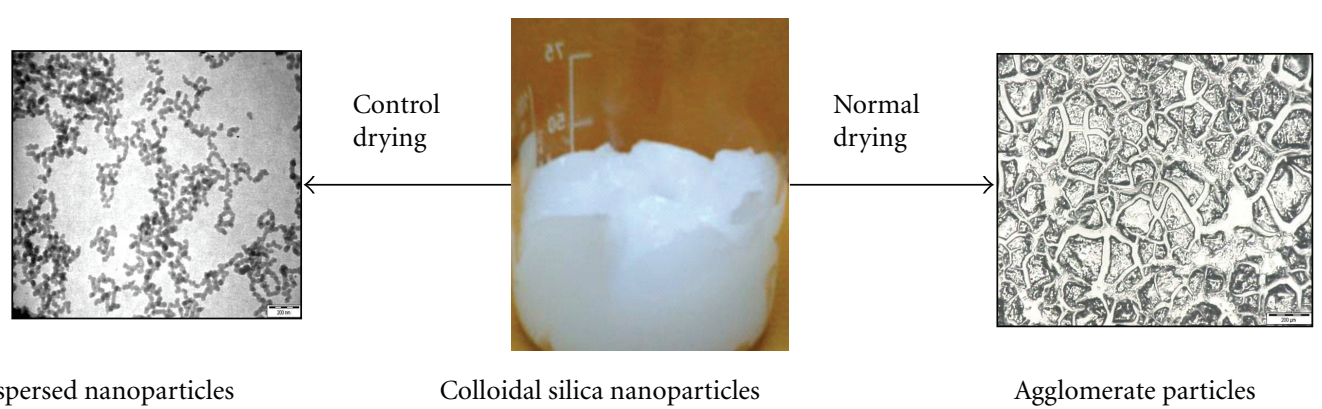

FIGURE 6: Morphology of dried colloidal silica nanoparticles under controlled drying and normal drying in presence of water.

to the presence of moisture. In aqueous system, the agglomeration behavior was caused by condensation reactions at the interparticle contacts during the drying process. In addition, Brownian motion, hydrodynamic effect, and capillary drag during the drying process can also contribute to the agglomeration behavior. Thus, agglomeration of nanoparticles during drying process could be effectively reduced by using ethanol as the suspension medium.

Rahman and coworkers [29] have described the effect of alcohol dehydration, freeze drying, and oven drying techniques on the size, size distribution, dispersion, and agglomeration of $\sim 7 \mathrm{~nm}$ nanosilica produced by sol-gel. The results revealed that alcohol dehydration was an effective technique to produce silica nanoparticles with improved dispersion and reduced agglomeration.

3.3. Size-Dependent Properties of Silica Nanoparticles. The properties of nanomaterials are usually size dependent. The nanomaterial often exhibits unique physical and chemical properties compared to the bulk counterparts. As described earlier, literatures describing the size-dependent properties of silica nanoparticles are not much available. Some of the properties such as specific surface area and photoluminescence properties with respect to the particle size are scarcely reported. Therefore, in this section, some general size-dependent properties of nanoceramics will be briefly discussed.

3.3.1. Physiochemical Properties. The amount of atoms residing on the surface increases with the decrease in particle size [2]. For silica nanoparticles smaller than $5 \mathrm{~nm}$, more than half of the $\mathrm{Si}$ atoms are present on the surface. Thus, the surface should have one or more silanol groups ( $\equiv \mathrm{Si}-\mathrm{OH})$ [16]. Therefore, the extent of chemical modification of silica such as grafting of organofunctional groups and incorporation of metal ions highly depends on the concentration of silanol groups per grams of silica. The number of silanol groups per unit area of silica provides information regarding the distribution of silanol groups on the silica surface [30]. The concentration of silanol groups increases with the decrease in the particles size which is interrelated to the specific surface area (Figures 7 and 8 ). However, the silanol number decrease with the decrease in the particle size suggests that these

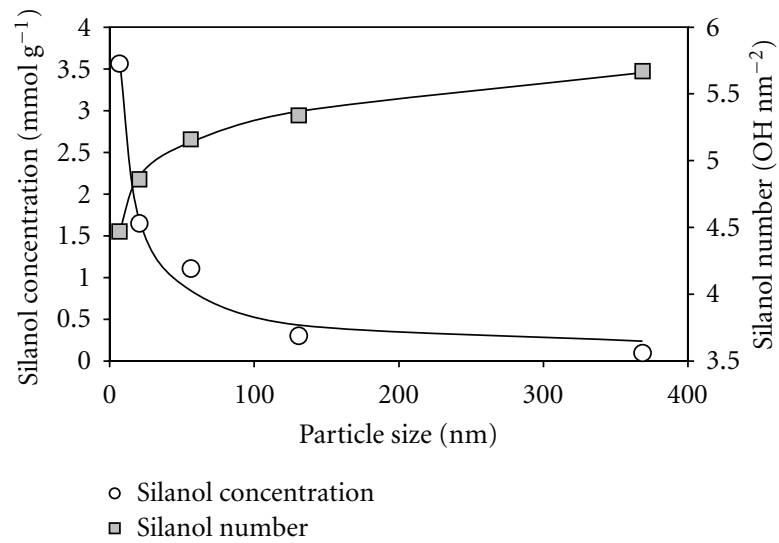

FIGURE 7: Variation of silanol concentration and silanol number with particle size of silica [30].

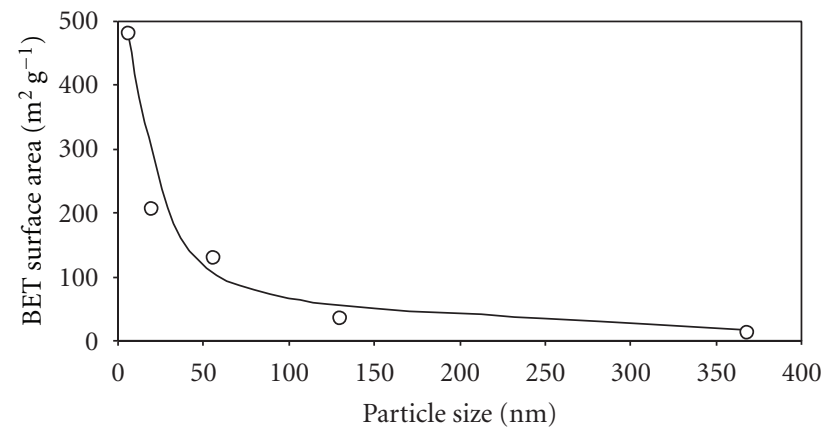

FIGURE 8: Variation of BET surface area with particle size of the silica [30].

nanoparticles could be chemically reactive, therefore suitable for catalyst applications.

Unusual adsorption properties are one of the remarkable properties of ceramic nanoparticles. Compared to the conventional and commercial counterparts, the nanoparticles shows enhanced ability to chemically adsorb and even disassociate a variety of hazardous organic molecules [2]. This unique adsorption property is directly related to the increase in surface area at nanoscale $[31,32]$.

3.3.2. Thermal and Mechanical Properties. Nanosize powders were found to compact easily, and the sintering temperature 
also significantly reduced compared to the conventional microsize powders. For example, the sintering of $\sim 20 \mathrm{~nm}$ fumed silica particles up to transparency was achieved at $1200^{\circ} \mathrm{C}$ [33] compared to the $1.6 \mu \mathrm{m}$ particles, which requires up to $1600^{\circ} \mathrm{C}$ to achieve transparency [34]. This unique sintering property is attributed to the high surface area of the nanoparticles which provides higher particle contacts than the conventional particles. Besides, ceramic nanoparticles also exhibit reduced brittleness and enhanced ductility. These interesting properties make the materials made from nanoscale ceramics more reliable compared to the conventional ceramics.

3.3.3. Optical Properties. Silica nanoparticles have been widely studied owing to several interesting optical phenomena caused by point defects generated from any defect imperfect $\mathrm{SiO}_{4}$ continuous network, including oxygen and silicon vacancies. Numerous typical defects for silica nanoparticles, for examples, surface $\mathrm{E}^{\prime}$ centers (paramagnetic positively charged oxygen vacancies, $\equiv \mathrm{Si} \bullet \mathrm{Si} \equiv$, or neutral dangling $\mathrm{Si}$ bonds, $\equiv \mathrm{Si}^{\bullet}$ ), self trapped exciton (photoexcited electronhole pairs; STE), nonbridging oxygen hole centers (NBOHC; dangling oxygen bonds, $\equiv \mathrm{Si}-\mathrm{O}^{*}$ ), neutral oxygen deficient centers (ODCs; $\equiv \mathrm{Si}-\mathrm{Si} \equiv$ ), twofold coordinated silicon lone pair centers $(\equiv \mathrm{Si}-\mathrm{O}-\mathrm{Si}-\mathrm{O}-\mathrm{Si} \equiv)$ hydrogen-related species $(\equiv \mathrm{Si}-\mathrm{H}$ and $\equiv \mathrm{Si}-\mathrm{OH})$, and interstitial $\mathrm{O}_{2}$ molecules [3539]. These point defects can also be divided into two groups: paramagnetic and diamagnetic. Paramagnetic defects have optical absorption which represents half-occupied energy level in the optical band gap. Thus, hole transition or electron transition to the valence band is possible. Diamagnetic defects have absorption band associated with electron transition to the conduction band [38]. These defects and their combination are able to exhibit diversity of absorption and PL bands in broad range of wavelength, near-infrared, visible, and ultraviolet (UV). Hence, optical absorption and photoluminescence (PL) become two useful tools for monitoring optical changes resulting from structural defect at the nanoparticle bulk and surface.

Chen [40] discovered a unique blue shift in the blue band $(2.8 \mathrm{eV})$ of the photoluminescence (PL) spectra while studying the PL behavior of 7 and $15 \mathrm{~nm}$ silica particles. The blue shift was reported to originate from electron-hole recombination of the self-trapped exciton (STE) in smallersized silica nanoparticle. The green $(2.35 \mathrm{eV})$ and red $(1.9 \mathrm{eV})$ bands in the PL spectra were attributed to the hydrogen-related species and nonbridging oxygen in the silica nanoparticles, respectively. This proved that the PL behavior arises from the phonon-assisted PL due to the thermalization of the silica nanoparticle system during laser irradiation. Rao et al. [25] reported the width of UV-Vis absorption peak at $\sim 525 \mathrm{~nm}$ varies with particle size. The change is believed due to the different interactions between different sizes of silica nanoparticles. However, a clear understanding on the relationship between the particle size and particle-particle interactions is not elaborated.

Relating to the discussion above, the optical emission properties of different size of silica nanoparticles have been characterized by using PL spectroscopy [30]. In general, the spectra contain two main bands located in the green $(\sim 2.35 \mathrm{eV})$ and blue $(\sim 2.85 \mathrm{eV})$ spectral ranges (Figure 9). These two bands were clearly observed for all the samples except for $\sim 369 \mathrm{~nm}$ silica (only green band at very low intensity was observed). This indicates that silica particles equal or larger than $\sim 400 \mathrm{~nm}$ are relatively less PL active.

The green band is attributed to the presence of Si$\mathrm{H}$ species at the silica surface $[41,42]$. A water molecule (retained by silanol groups) that is confined between two nanoparticles is expected to produce two Si-H species. Due to the silanol concentration increased with the decrease in the particle size, the concentration of $\mathrm{Si}-\mathrm{H}$ species are expected to increase in the same manner. This explains the increase in the green band intensity for the silica nanoparticles is about $\sim 369 \ll \sim 130<\sim 21<\sim 7$. The slight blue-shift observed for the green bands of $\sim 7$ and $\sim 21 \mathrm{~nm}$ relative to other sizes could be attributed to the stabilization of $\mathrm{Si}-\mathrm{H}$ species through intraparticle and/or interparticle interactions. On the other hand, the blue band observed for $\sim 7, \sim 21$, and $\sim 130 \mathrm{~nm}$ has been suggested to originate from electron-hole recombination of self-trapped exciton (STE) $[40,43]$ and oxygen-deficient centers (ODC) (neutral oxygen vacancies: $\equiv \mathrm{Si}-\mathrm{Si} \equiv$ and twofold coordinated silicon defects: $\equiv \mathrm{Si}-\mathrm{O}-$ $\mathrm{Si}-\mathrm{O}-\mathrm{Si} \equiv)$ [44, 45]. The increase in intensity of the blue band with the decrease in the particle size (Figure 9) could be due to higher concentration of defect sites (STE and ODC) at smaller particle sizes. These findings are almost consistent with results obtained by Chen [40]. In contrast, we did not observe any red band or blue-shift (for the blue band) which is possibly due to the different origins of the silica used in both studies (Aerosil, Degussa versus inhouse silica nanoparticles). In general, the unique optical properties of silica nanoparticles, especially below $10 \mathrm{~nm}$, can be further enhanced by incorporation with functionalized groups or metal ions to yield unique optical devices and offer additional advantages associated with a lower-temperature fabrication procedure.

\section{Silica-Filled Polymer Nanocomposites}

One of the prominent applications of silica nanoparticles is as fillers or reinforcement in advanced composite materials. One of the important aspects of silica-polymer nanocomposite is the ability to attain homogenous filler dispersion, which determines the overall performance of the nanocomposites. Chemical modifications of silica (filler) surface and effective mixing method are two main routes that can lead to homogenous filler distribution. On the other hand, the performance of a nanocomposite also depends on the type of polymeric matrix used.

The following sections briefly review the important aspects of silica-polymer nanocomposites, as stated above, such as chemical modification of silica surface, the preparation method for nanocomposites, and the effect of silica nanoparticles on the properties of nanocomposites.

4.1. Chemical Modification of Silica Surface. The chemical modification of silica surface with organofunctional groups 


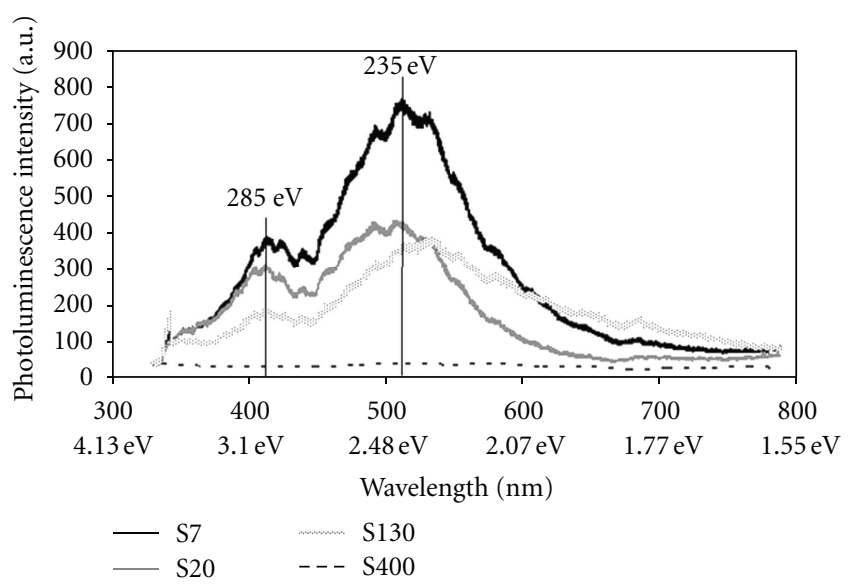

Figure 9: PL spectra of different sizes ( $\mathrm{S} 7=\sim 7 \mathrm{~nm}, \mathrm{~S} 20=\sim 21 \mathrm{nmm}, \mathrm{S} 130=\sim 130 \mathrm{~nm}, \mathrm{~S} 400=\sim 369 \mathrm{~nm}$ ) of silica nanoparticles [30].

is an important step towards the preparation of silica-polymer nanocomposites. More precisely, the surface modifications have been reported to enhance the affinity between the organic and inorganic phases and at the same time improve the dispersion of silica nanoparticles within the polymer matrix [3, 46-51].

Modification of silica surface with silane coupling agents is one of the most effective techniques available. Silanecoupling agents $\left(\mathrm{Si}(\mathrm{OR})_{3} R^{\prime}\right)$ have the ability to bond inorganic materials such as silica nanoparticles to organic resins. In general, the $\mathrm{Si}(\mathrm{OR})_{3}$ portion of the silane-coupling agents reacts with the inorganic reinforcement, while the organofunctional group $\left(R^{\prime}\right)$ reacts with the resin. Table 2 shows some of the common silane coupling agents used for modification of silica surface.

In general, the chemical modification of silica surface using silane coupling agents can be conducted via aqueous or nonaqueous system that is also known as postmodification. The nonaqueous system is usually used for grafting APTS molecules onto the silica surface. The main reason for using non-aqueous system is to prevent hydrolysis. Silanes such as APTS which carries amine groups (base) can undergo uncontrollable hydrolysis and polycondensation reactions in the aqueous system. Therefore, the use of organic solvent provides a better control of reaction parameters and preferred for coupling reaction using APTS. For nonaqueous system, the silane molecules are attached to the silica surface via direct condensation reaction and the reaction usually conducted at reflux conditions [6]. On the other hand, the aqueous system is favorable for large-scale production. In this system, the silanes undergo hydrolysis and condensation before deposition on the surface (Figure 10). The alkoxy molecules are hydrolyzed in contact with water. This is followed by self-condensation reactions between the hydrolyzed silanes. Then, the silane molecules are deposited on the silica surface through formation of siloxane bonds between the silanol groups and hydrolyzed silanes with the release of water molecules [6].

Surface modification of silica nanoparticles can be carried out by using various types of silane coupling agents such

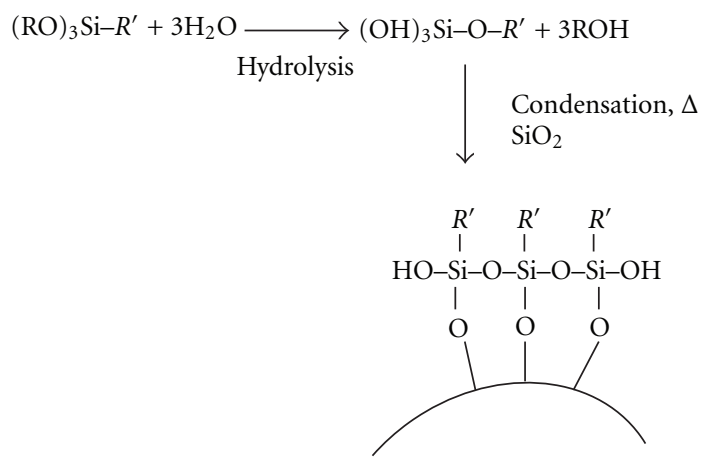

Figure 10: Chemical modification of silica surface in aqueous system.

as aminopropylmethydiethoxy silane (APMDS) and methacryloxypropyltriethoxysilane (MPTS) via nonaqueous and aqueous route $[46,47]$. A slight increase in the particle size $(\sim 25 \%)$ after the surface modification was observed [47].

Sun and coworkers [52] reported the effect of surface modification on the dispersion of silica nanoparticles for potential application as underfill material in semiconductor packaging. Two types of silanes: aminoethylaminopropyltrimethoxy-silane (AEAPTS) and 3-glycidyloxypropyltriethoxysilane (GPTS) carrying amino and epoxy groups, respectively, were used to activate the surface of $90 \mathrm{~nm}$ silica particles.

The treatment of nanosilica by epoxy silane with a longer reaction time and lower silane concentrations assisted with pretreatment by sonication can achieve monodispersed silica in polar medium. Both modification reactions were conducted via aqueous route. It was reported that the epoxy silane was more effective in dispersing the silica nanoparticles compared to the amino silanes due to the absence of hydrogen bonding between the particles. The total loading of amino and epoxy silanes were found to be $9.75 \%$ and $10.12 \%$, respectively. In a much recent work, Pham et al. [49] conducted surface modification on $30 \mathrm{~nm}$ colloidal silica particles using 3-aminopropyltrimethoxysilane (APTS) and 


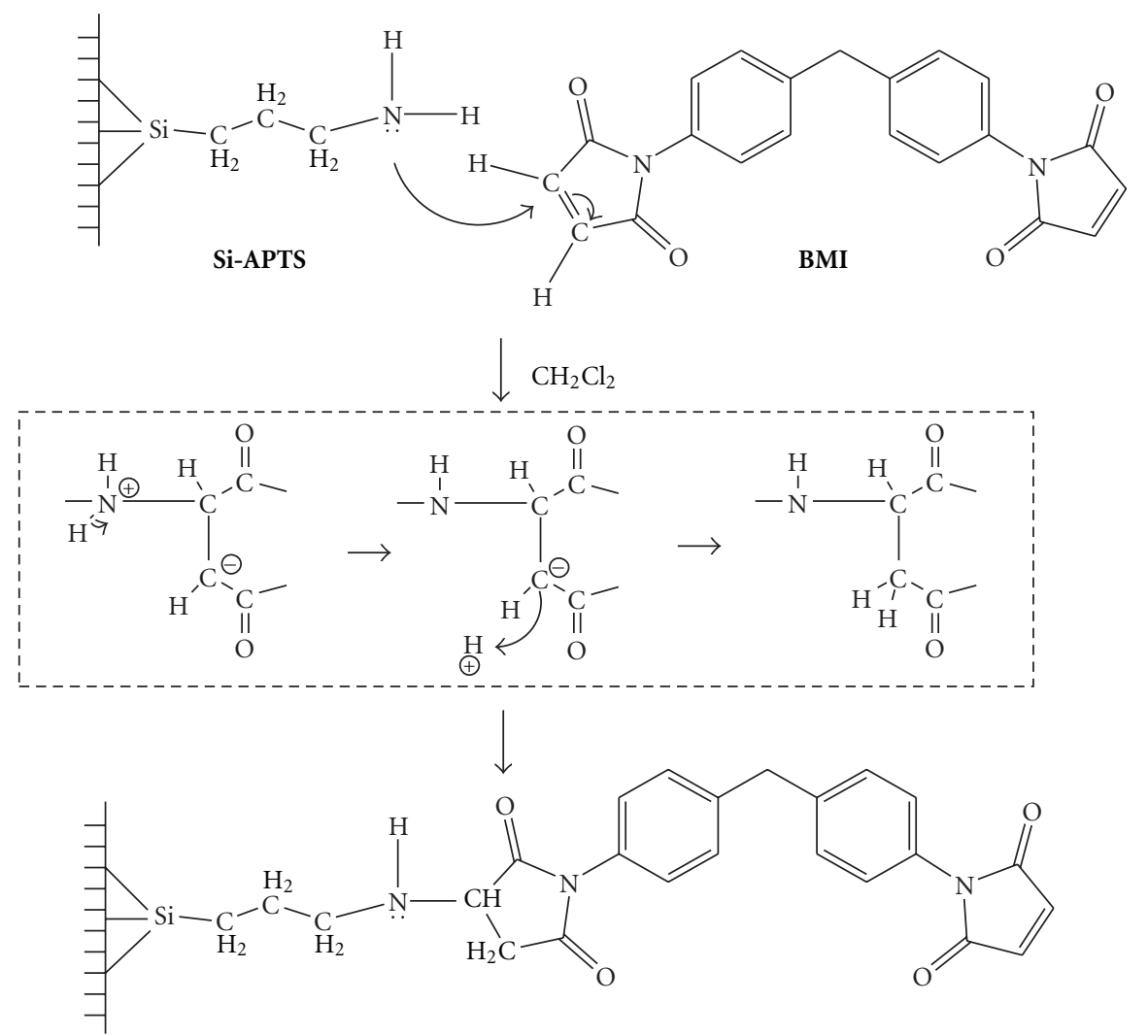

Si-APTS-BMI

FIGURE 11: Nucleophilic addition mechanism between primary amine and maleimide double bonds.

TABLE 2: Silane-coupling agents commonly used.

\begin{tabular}{ll}
\hline Name (acronym) & Formula \\
\hline Vinyltriethoxysilane (VTS) & $\left(\mathrm{C}_{2} \mathrm{H}_{5} \mathrm{O}\right)_{3} \mathrm{Si}-\mathrm{CH}_{2} \mathrm{CH}_{2}$ \\
Methacryloxypropyltriethoxysilane (MPTS) & $\left(\mathrm{C}_{2} \mathrm{H}_{5} \mathrm{O}\right)_{3} \mathrm{Si}-\mathrm{CH}_{2} \mathrm{CH}_{2} \mathrm{CH}_{2}-\mathrm{O}-\mathrm{CO}-\mathrm{C}(\mathrm{CH})_{3}=\mathrm{CH}_{2}$ \\
3-Glycidyloxypropyltrimethoxysilane (GPTS) & $\left(\mathrm{CH}_{3} \mathrm{O}\right)_{3} \mathrm{Si}_{-}-\mathrm{CH}_{2} \mathrm{CH}_{2} \mathrm{CH}_{2}-\mathrm{O}-\mathrm{CH}_{2} \mathrm{CH}^{-} \mathrm{CH}_{2}$ \\
3-Aminopropyltrimethoxysilane (APTS) & \\
3-Mercaptopropyltriethoxysilane (McPTS) & $\left(\mathrm{CH}_{3} \mathrm{O}\right)_{3} \mathrm{Si}_{-}-\mathrm{CH}_{2} \mathrm{CH}_{2} \mathrm{CH}_{2} \mathrm{NH}_{2}$ \\
Chloropropyltriethoxysilane (CPTS) & $\left(\mathrm{C}_{2} \mathrm{H}_{5} \mathrm{O}\right)_{3} \mathrm{Si}_{-}-\mathrm{CH}_{2} \mathrm{CH}_{2} \mathrm{CH}_{2} \mathrm{SH}^{-}$ \\
\hline
\end{tabular}

3-aminopropyldimethylmethoxysilane (APMS) under aqueous conditions. The irreversible aggregation of silica nanoparticles in colloidal form can be controlled by keeping the trimethoxysilane to silica ratio low while mixing and reacting the two slowly or by using monomethoxysilane as the aminosilane surface modifying agent. These studies indicate that, for an efficient surface modification using the silane coupling agents one, must use low concentrations of silane solution and longer reaction time.

Vejayakumaran et al. [53] successfully grafted amino group onto $\sim 7 \mathrm{~nm}$ nanosilica in nonaqueous by using APTS. The grafted silica particles were further grafted with BMI monomer to form Si-BMI nanocomposite via nucleophilic addition as shown in Figure 11.
One-pot synthesis is an alternative approach in order to reduce time, energy, or other disadvantages of the postmodification approach. Cocondensation is one of common ways for the modification purpose, owing to homogeneously incorporation of organic functional group to the interior and exterior of the bulk of silica particle. Although numerous of cocondensation modification methods have been reported for porous silica, the modification of silica nanoparticles has been less investigated [54-57].

Nanosized organofunctionalized silica particles can be obtained through a modified Stöber method using TEOS or APTES in ethanol [54]. The triethanolamine-catalyzed synthesis of extremely small mesoporous silica nanoparticles via a specific cocondensation process with 
phenyltriethoxysilane has been demonstrated by Kobler and Bein [55]. The size of the suspended mesoporous silica spheres is reduced by decreasing the concentration of precursor and catalyst. Monodisperse colloidal suspensions of porous nanoparticles with the size of $40 \mathrm{~nm}$ are utilized for the preparation of transparent homogeneous thin film by spin-coating technique. An amino-functionalized monodispersed silica with different particle size of $310-780 \mathrm{~nm}$ has been synthesized by direct cocondensation of 3-aminopropyltrimethoxysilane (APTMS), [3-(2-aminoethylamino) propyl] trimethoxysilane (AEAP-TMS), or 3-[2-(2-aminoethylamino)ethylamino] propyltrimethoxysilane (AEAEAPTMS) with tetramethoxysilane [56]. The functionalized silica particles showed an excellent catalytic activity in the condensation reactions of nitroaldols.

An easy and swift pathway in preparation of amine-functionalized $\sim 60 \mathrm{~nm}$ nanosilica via cocondensation method in nonaqueous media using APTS as coupling agent was reported by Rahman et al. [57]. One Japanese group has prepared amino-functionalized silica nanoparticles from precursor mixtures of tetraethoxysilane and aminopropyltriethoxysilane in ethanol/water solutions via a one-pot solgel procedure [58]. In their method, particles with the diameter less than $200 \mathrm{~nm}$ have been obtained where the particle size and size distribution depend on the mixing ratios of the starting materials. The amino-functionalized silica particles have some potential biomedical applications such as carriers of enzymes, drugs, and DNA. Recently, one-pot water-oil-microemulsion technique has been used to synthesize functionalized silica nanoparticles ranging from 25 to $200 \mathrm{~nm}$ in a mixture of TEOS, organosilanes (3-aminopropyltriethoxysilane (APTES), 3-mercaptopropyltrimethoxysilane (MPTMS), phenyltrimethoxysilane (PTMS), vinyltriethoxysilane (VTES), and polyoxyethylene nonylphenol ether [59].

Comparing between the two modification methods, one realize that the postmodification does not much affect the size and size distribution of the particles, where as one-pot synthesis produces a much bigger particles, of course, with low aggregation. This is due to the presence of $\mathrm{NH}_{2}$ group that leads to the increment in the rate of hydrolysis which induces particles growth. For this reason, the use of a small amount of silane coupling agent is an advantage.

4.2. Methods for Dispersing Silica Nanoparticles in Polymer Matrix. The techniques commonly used for the silica-polymer nanocomposite production can be categorized into three classes, that is, (i) solution mixing, (ii) in situ polymerization process, and (iii) melt mixing processes [60]. The solution and in situ polymerization processes usually produce higher levels of nanoparticle dispersion. However, melt mixing process finds favor due to its compatibility with current industrial compounding facilities. In addition, the absence of solvents makes the process environmentally benign and economically favorable. In the melt mixing processes, polymer molecules gain increased mobility through an input of thermal energy and are mixed with the fillers mechanically. In fact, melt mixing is the most favored technique to prepare the contemporary BMI-based nanocomposites [61-64]. As an example, Meng et al. [62] prepared the BMI-DABPA(O,Odiallyl bisphenol A)-clay nanocomposite by first homogenously mixing DABPA and clay (2 hours), followed by melt mixing of the mixture with $\mathrm{BMI}$ at $130^{\circ} \mathrm{C}$. Mechanical stirrer or high-speed homogenizers are usually employed to facilitate the homogenous mixing of fillers within polymer melts. Besides, ultrasonication is also commonly used to effectively disperse the nanoparticles within the polymer matrix [52].

Thus, a homogenous dispersion of nanofillers via melt mixing process is still a challenging aspect in the preparation polymer composite materials. Intense particle-particle attractions at nanoscale and the presence of monomers and curing agents in solid form at room temperature require effective dispersion techniques. In our unpublished work, $7 \mathrm{~nm}$ nanosilica particles have been homogeneously dispersed in a matrix of $1,1^{\prime}$-(methylenedi-4,1-phenelene) bismaleimide and $1,1^{\prime}$-diaminodiphenylmethane (BMI-DDM). The combination of pretreatment of nanosilica particles with ultrasonic radiation and heat, followed by agitation in BMI melt, was found to be highly effective in breaking the soft aggregates of nanosilica particles and improving the dispersion in the BMI/DDM matrix as compared to melt mixing method (Figure 12).

\subsection{Applications of Nanosilica in Polymer Nanocomposites.} Due to the large boundary surface created by the silica nanoparticles (fillers), it is possible to produce silica-polymer nanocomposites with new and improved properties. The advantages of nanoparticles include efficient reinforcement with excellent mechanical strength, heat stability, reduced shrinkage, thermal expansion and residual stress, improved abrasion resistance, and enhanced optical and electric properties. The decrease of particle size below $100 \mathrm{~nm}$ enables good optical transparency, especially for silica. In addition, nanoparticles offer various property enhancements at lower loadings due to higher surface-to-volume ratio compared to the conventional particles. Therefore, nanocomposites offer exciting properties which permit their use in automotive, aerospace, electronic, and engineering applications. Table 3 summarizes various types of silica-based nanocomposites together with the resulting properties as reported in literatures $[46,59,65-79]$. The summary shows that the epoxies dominate over other polymers as the matrix of silica-polymer nanocomposites.

As shown in Table 3, silica nanoparticle reinforcement in certain polymer matrixes can lead to significant property improvements, whereas in others they only provide marginal property improvements or in some cases worsening of the properties. As an example, Kang et al. [46] found that the incorporation of $400 \mathrm{~nm}$ silica particles into epoxy resulted in almost $13 \%$ increase in the $T_{g}$ and the damping behavior $(\tan \delta)$ of the composite decreased with the increase in the filler content. These phenomena have been attributed to the addition of rigid silica nanoparticle which made the polymer difficult to move.

By contrast, Zhang et al. [65], as shown in Figure 13, observed a decreasing trend in the $T_{g}$ value at increasing filler content due to the plasticization effect exerted by 
TABLE 3: Various types of silica-polymer nanocomposites reported in the literature together with the details on filler sizes, concentrations, and some selected results.

\begin{tabular}{|c|c|c|c|c|}
\hline Polymer matrix & Silica size (nm) & Silica content & $\begin{array}{l}\text { Major property changes (with increasing filler } \\
\text { content) }\end{array}$ & Reference \\
\hline Polyurethane & 175,395 and 730 & $1-10$ wt. $\%$ & $\begin{array}{l}\text { Constant } T_{g} \text { at different particle size and } \\
\text { concentrations }\end{array}$ & {$[66]$} \\
\hline Epoxy (DGEBA) & 400 & $50-70$ wt. $\%$ & $\begin{array}{l}\text { (i) Decreased CTE and increased } T_{g} \\
\text { (ii) Increased brittleness }\end{array}$ & {$[46]$} \\
\hline Epoxy (DGEBF) ${ }^{\mathrm{a}}$ & 90 & $1-7$ wt.\% & $\begin{array}{l}\text { (i) Increased fracture toughness } \\
\text { (ii) Larger deformation resistance (up to } 3 \text { wt. \%) }\end{array}$ & [67] \\
\hline Polyimide & 20 & $10-50$ wt. $\%$ & $\begin{array}{l}\text { (i) Increased dielectric constant } \\
\text { (ii) Enhanced thermal stability }\end{array}$ & {$[68]$} \\
\hline Epoxy (commercial) & 25 & 1-14 vol.\% & $\begin{array}{l}\text { (i) Decreased } T_{g} \text { and increased } T_{\beta} \\
\text { (ii) Increased microhardness, fracture toughness, } \\
\text { and modulus }\end{array}$ & {$[65]$} \\
\hline $\begin{array}{l}\text { Thermoplastic } \\
\text { polyurethane }\end{array}$ & 7 & 10 wt. $\%$ & $\begin{array}{l}\text { (i) Decreased } T_{g} \\
\text { (ii) Increased shear and storage modulus } \\
\text { (iii) Increased tensile and peel strength }\end{array}$ & [69] \\
\hline Epoxy (DGEBA) ${ }^{\mathrm{b}}$ & $240 \& 1560$ & 30 vol. $\%$ & $\begin{array}{l}\text { (i) Increased storage and loss modulus } \\
\text { (ii) Decreased } T_{g} \text { with the increase in the fraction } \\
\text { of } 1560 \mathrm{~nm} \text { particles }\end{array}$ & {$[70]$} \\
\hline Epoxy (commercial) & N/A & $10-30 \mathrm{phr}$ & $\begin{array}{l}\text { (i) Decreased } T_{g} \text { (up to } 20 \mathrm{phr} \text { ) } \\
\text { (ii) Decreased storage modulus and elastic } \\
\text { modulus (up to } 20 \mathrm{phr} \text { ) }\end{array}$ & [71] \\
\hline Epoxy (DGEBA) & 75 and 330 & $1-5$ wt. $\%$ & $\begin{array}{l}\text { (i) Increased aggregation level } \\
\text { (ii) Increased elastic modulus (modeled) } \\
\text { (iii) Higher modulus for smaller particles }\end{array}$ & {$[72]$} \\
\hline Epoxy $\left(\right.$ TGDDM) ${ }^{c}$ & 12.5 & 5 and 10 wt. $\%$ & $\begin{array}{l}\text { (i) Decreased } T_{g} \text {, constant } T_{\beta} \\
\text { (ii) Increased elastic and yield modulus } \\
\text { (iii) Increased brittle fractureness }\end{array}$ & {$[73]$} \\
\hline Epoxy (DGEBA) & $10-20$ & $10-70$ wt. $\%$ & $\begin{array}{l}\text { (i) Decreased } T_{g} \\
\text { (ii) Increased thermal stability }\end{array}$ & {$[74]$} \\
\hline Acrylic polymer ${ }^{\mathrm{d}}$ & $15-20$ & $10-50$ wt. $\%$ & $\begin{array}{l}\text { (i) Increased thermal stability } \\
\text { (ii) Enhanced hardness } \\
\text { (iii) Excellent optical transparency }\end{array}$ & {$[75]$} \\
\hline Epoxy & 4000 & 14-39vol.\% & $\begin{array}{l}\text { (i) Increased Young's modulus } \\
\text { (ii) Immonotonic variation in the yield strength } \\
\text { and yield stress }\end{array}$ & {$[76]$} \\
\hline Epoxy $(B P A)^{e}$ & 9 & 2.17 vol. $\%$ & $\begin{array}{l}\text { (i) Decreased frictional coefficient and specific } \\
\text { wear rate } \\
\text { (ii) Modified silica nanoparticles promote cure } \\
\text { reaction of epoxy }\end{array}$ & {$[77]$} \\
\hline Polyurethane & $14-260$ & $1-4$ wt. $\%$ & $\begin{array}{l}\text { (i) Increased } T_{g} \\
\text { (ii) } T_{g} \text { increased with particle size up to } 66 \mathrm{~nm} \\
\text { and then decreased } \\
\text { (iii) Decreased surface and interface free energies } \\
\text { by incorporation silica }\end{array}$ & {$[78]$} \\
\hline Polystyrene & $25-200$ & 5-10 wt.\% & $\begin{array}{l}\text { (i) Increased DTA peaks } \\
\text { (ii) Strong interaction between silanes group and } \\
\text { polymer chains }\end{array}$ & [59] \\
\hline Polyurethane & 30 & 5 & Increased $\mathrm{SiO}_{2}$ dispersion & [79] \\
\hline Polypropylene & $50-110$ & $1-5$ wt. $\%$ & $\begin{array}{l}\text { (i) Larger thermal degradation stabilization } \\
\text { (ii) Larger elastic modulus }\end{array}$ & {$[85]$} \\
\hline
\end{tabular}

${ }^{a}$ Diglycidylether of bisphenol F; ${ }^{b}$ Diglycidylether of bisphenol A; ${ }^{\mathrm{c}}$ Tetraglycidyl 4-4'-diaminodiphenylmethane; ${ }^{\mathrm{d}}$ Based on 3-(trimethoxysilyl)propyl methacrylate; ${ }^{\mathrm{e} B i s p h e n o l ~ A ~ e p o x y ~ r e s i n ~(t y p e ~ E-51) . ~}$ 


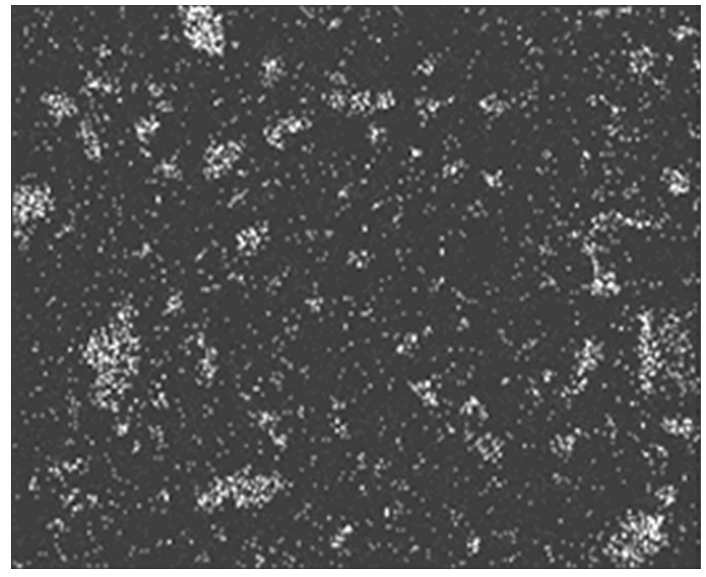

$100 \mu \mathrm{m}$

(a) Direct melting process

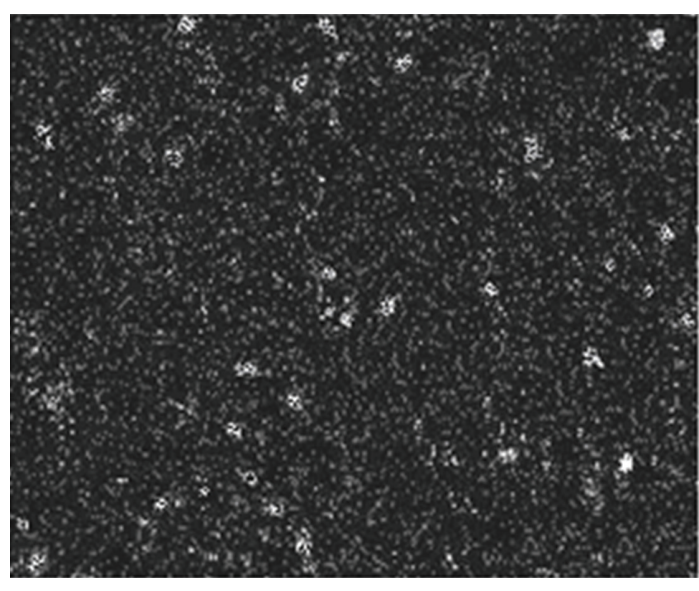

$100 \mu \mathrm{m}$

(b) Pretreatment process

FIGURE 12: SEM-EDX Si mapping showing the distribution of silica in silica-bismaleimide nanocomposites (bright spots indicate Si elements from the fillers).

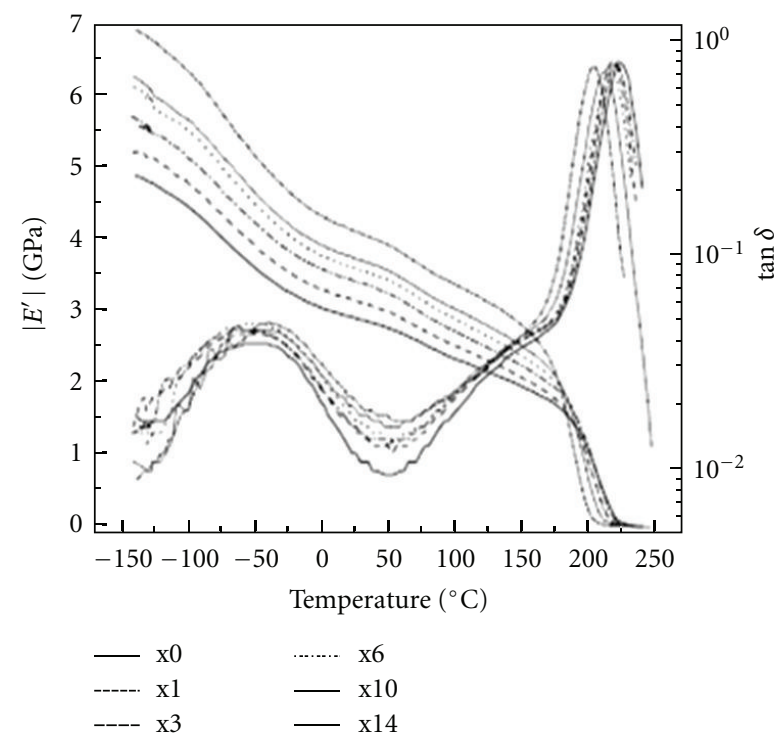

(a)

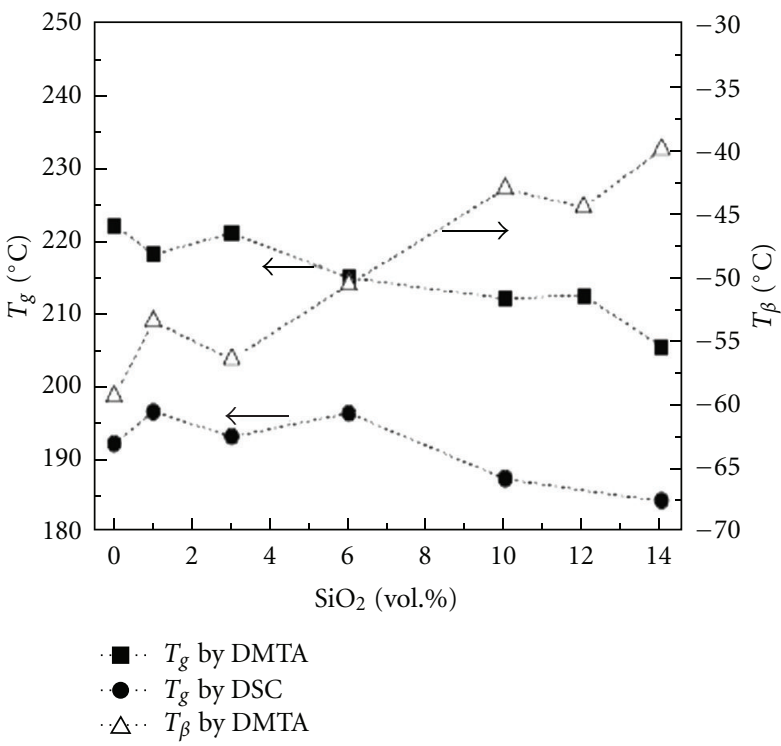

(b)

Figure 13: (a) Complex modulus and damping behavior, and (b) first and second glass transition temperatures $\left(T_{g}\right.$ and $\left.T_{\beta}\right)$ as a function of nanosilica volume fraction, as reported by Zhang et al. [65].

$25 \mathrm{~nm}$ colloidal silica particles. However, they found the $T_{\beta}$ increased with the increasing filler content. Nevertheless, the authors did not explain this trend. On the contrary, the authors found an enhanced modulus in presence of silica nanoparticles (Figure 13). The enhancement in modulus is due to the large difference in CTE of the filler and matrix, which may provide additional stress transfer under loading.

On the other hand, Preghenella et al. [71] found an immonotonous variation in the thermomechanical properties of fumed silica filled epoxy composite with respect to the filler content. The $T_{g}$ was found decreased up to $27 \%$ as the filler content was increased from 0 to $20 \mathrm{phr}$. However, the $T_{g}$ was found increased at $30 \mathrm{phr}$ of silica content. According to the authors, the inversion in properties trend at the highest silica content was supposed to be due to the enhanced physical immobilization effect experienced by the polymer matrix near the percolation threshold of the filler. In another work, Zhang et al. [77], based on the DSC kinetic studies, found that the polyacrylamide- (PAAM-) modified silica nanoparticles slightly enhance the cure reactions of epoxy. Contrary effect was found for nonmodified silica nanoparticles. This interesting findings show that the silica nanoparticles not 


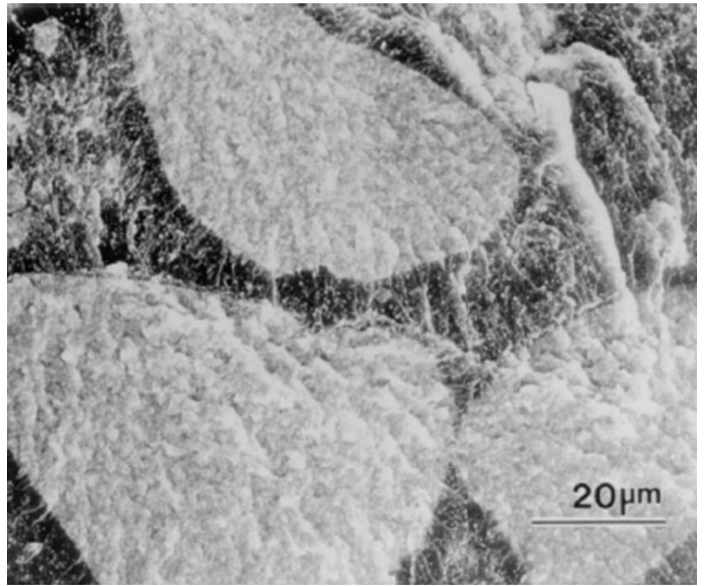

(a)

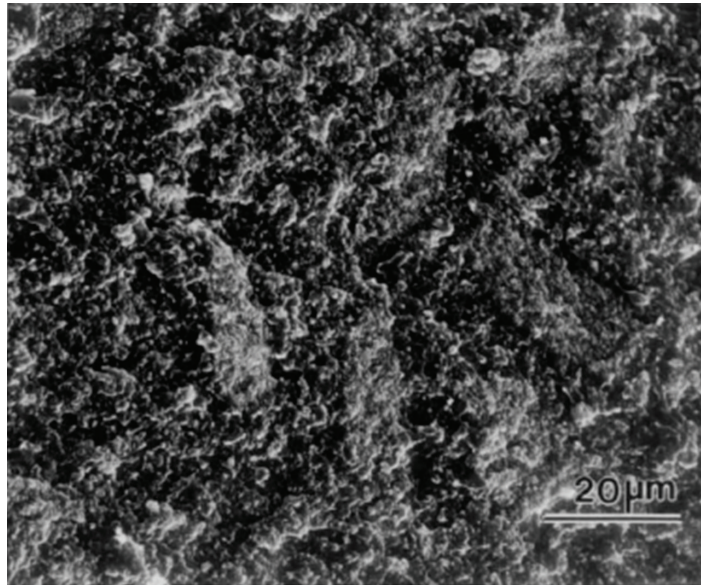

(b)

FIGURE 14: SEM micrographs of fractured epoxy nanocomposites filled with (a) pure silica and (b) surface modified (with epoxide functionalities) silica nanoparticles by $70 \mathrm{wt} . \%$ as reported by Kang et al. [46].

only influence the thermal mechanical properties of the nanocomposite but also play a part in the polymerization reactions of the polymer matrix, in some cases.

4.4. Filler-Matrix Interactions. The interaction at the interface between the nanofillers and matrix is the most important factor that controls the resulting properties of the nanocomposite [3]. A strong interface between the filler and matrix can be achieved through surface modification that leads to significantly reduced filler agglomeration [46], as shown in Figure 14. The phenomena may be due to the interaction between functional group on the filler surface with polymer chains that increased surface charge and enhanced dispersion. The SEM analysis showed that the pure silica nanoparticles present as large aggregates (Figure 14(a)) in the epoxy matrix. Significant improvement in the dispersion was achieved by modifying the silica surface with epoxide functional groups (Figure 14(b)). Better thermal properties ( $T_{g}$ and CTE) were observed for the composites prepared from epoxide-modified silica nanoparticles compared to the pure silica. Ragosta et al. [73] found that the epoxy groups reacted with the silanol groups present on the silica surface, leading to an increased interfacial adhesion. The strong interfacial adhesion increased the fracture toughness of silica-epoxy nanocomposite compared to the neat epoxy. Zhang et al. [77] found an enhanced wear resistance in the silica-epoxy nanocomposite prepared from polyacrylamide(PAAM-) modified silica nanoparticles. This enhancement was attributed to the covalent bonding between the PAAMmodified silica and epoxy matrix. These literature studies show that it is paramount important to modify the silica surface to attain stronger interface between the fillers and polymer matrix and also to improve the filler dispersion.

The strong surface interaction at the filler-polymer interface is related to the formation immobilized amorphous layer of polymer molecules on the nanoparticles. The thickness of the layer depends on the degree of dispersion, size, and types of nanofillers but independent from their shapes that resulted in unique properties of nanocomposites [80-84]. Thus, the use of nanosize fillers offers a great benefit to the nanocomposites compared to the traditional composites.

\section{Summary}

Silica nanoparticles are widely applied as fillers in silica-polymer nanocomposites. The most commonly used route for synthesizing silica nanoparticles is sol-gel method due to its ability to produce monodispersed with narrow-size distribution nanoparticles at mild conditions. However, a critical challenge in the preparation of nanocomposites is the homogeneity in the mixing between the filler and organic components. This can be achieved through surface modification of silica by using silane-coupling agents. Other than applications covered in this paper, surface modification makes the possibility to graft or conjugate the nanostructured silica with polymers or proteins for future applications in biotechnology and medicine such as dental filling composites, cancer treatment, and drug delivery. We hope that this paper will provide some insight knowledge in synthesis of nanosilica by sol-gel and surface modification process for researchers working in nanocomposites.

\section{Acknowledgment}

The authors thank Universiti Sains Malaysia for financing this work through Grant no. 1001/PPSG/814110.

\section{References}

[1] K. E. Drexler, Engines of Creation: The Coming era of Nanotechnology, Doubleday/Anchor Press, New York, NY, USA, 1986.

[2] K. J. Klabunde, Nanoscale Materials in Chemistry, Wiley-Interscience, New York, NY, USA, 2001.

[3] G. Kickelbick, "Concepts for the incorporation of inorganic building blocks into organic polymers on a nanoscale," Progress in Polymer Science, vol. 28, no. 1, pp. 83-114, 2003. 
[4] Q. H. Zeng, D. Z. Wang, A. B. Yu, and G. Q. Lu, "Synthesis of polymer-montmorillonite nanocomposites by in situ intercalative polymerization," Nanotechnology, vol. 13, no. 5, pp. 549-553, 2002.

[5] Z. Wang and J. T. Pinnavaia, "Nanolayer reinforcement of elastomeric polyurethane," Chemistry of Materials, vol. 10, no. 12, pp. 1820-1826, 1998.

[6] E. F. Vansant, P. V. D. Voort, and K. C. Vrancken, Characterization and Chemical Modification of the Silica Surface, Elsevier Science, New York, NY, USA, 1995.

[7] E. Reverchon and R. Adami, "Nanomaterials and supercritical fluids," Journal of Supercritical Fluids, vol. 37, no. 1, pp. 1-22, 2006.

[8] T. T. Y. Tan, S. Liu, Y. Zhang, M.-Y. Han, and S. T. Selvan, "Microemulsion preparative method (Overview)," Comprehensive Nanoscience and Technology, vol. 5, pp. 399-441, 2011.

[9] S. Liu and M.-Y. Han, "Silica-coated metal nanoparticles," Chemistry, vol. 5, no. 1, pp. 36-45, 2010.

[10] R. P. Bagwe, L. R. Hilliard, and W. Tan, "Surface modification of silica nanoparticles to reduce aggregation and nonspecific binding," Langmuir, vol. 22, no. 9, pp. 4357-4362, 2006.

[11] G. A. Silva, "Introduction to nanotechnology and its applications to medicine," Surgical Neurology, vol. 61, no. 3, pp. 216220, 2004

[12] K. J. Klabunde, J. Stark, O. Koper et al., "Nanocrystals as stoichiometric reagents with unique surface chemistry," The Journal of Physical Chemistry, vol. 100, no. 30, pp. 1214212153, 1996.

[13] L. L. Hench and J. K. West, "The Sol-Gel process," Chemical Reviews, vol. 90, no. 1, pp. 33-72, 1990.

[14] W. Stöber, A. Fink, and E. Bohn, "Controlled growth of monodisperse silica spheres in the micron size range," Journal of Colloid And Interface Science, vol. 26, no. 1, pp. 62-69, 1968.

[15] G. H. Bogush, M. A. Tracy, and C. F. Zukoski, "Preparation of monodisperse silica particles: control of size and mass fraction," Journal of Non-Crystalline Solids, vol. 104, no. 1, pp. 95106, 1988.

[16] C. J. Brinker and G. W. Scherer, Sol-Gel Science: The Physics and Chemistry of Sol-Gel Processing, Academic Press, San Diego, Calif, USA, 1990.

[17] T. Matsoukas and E. Gulari, "Dynamics of growth of silica particles from ammonia-catalyzed hydrolysis of tetra-ethylorthosilicate," Journal of Colloid And Interface Science, vol. 124, no. 1, pp. 252-261, 1988.

[18] T. Matsoukas and E. Gulari, "Monomer-addition growth with a slow initiation step: a growth model for silica particles from alkoxides," Journal of Colloid And Interface Science, vol. 132, no. 1, pp. 13-21, 1989.

[19] G. H. Bogush and C. F. Zukoski, "Studies of the kinetics of the precipitation of uniform silica particles through the hydrolysis and condensation of silicon alkoxides," Journal of Colloid And Interface Science, vol. 142, no. 1, pp. 19-34, 1991.

[20] J. K. Bailey and M. L. Mecartney, "Formation of colloidal silica particles from alkoxides," Colloids and Surfaces, vol. 63, no. 12, pp. 151-161, 1992.

[21] K. Lee, A. N. Sathyagal, and A. V. McCormick, "A closer look at an aggregation model of the Stober process," Colloids and Surfaces A, vol. 144, no. 1-3, pp. 115-125, 1998.

[22] D. L. Green, J. S. Lin, Y. F. Lam, M. Z.-C. Hu, D. W. Schaefer, and M. T. Harris, "Size, volume fraction, and nucleation of Stober silica nanoparticles," Journal of Colloid and Interface Science, vol. 266, no. 2, pp. 346-358, 2003.

[23] I. A. Rahman, P. Vejayakumaran, C. S. Sipaut et al., "An optimized sol-gel synthesis of stable primary equivalent silica particles," Colloids and Surfaces A, vol. 294, no. 1-3, pp. 102110, 2007.

[24] S. K. Park, K. D. Kim, and H. T. Kim, "Preparation of silica nanoparticles: determination of the optimal synthesis conditions for small and uniform particles," Colloids and Surfaces A, vol. 197, no. 1-3, pp. 7-17, 2002.

[25] K. S. Rao, K. El-Hami, T. Kodaki, K. Matsushige, and K. Makino, "A novel method for synthesis of silica nanoparticles," Journal of Colloid and Interface Science, vol. 289, no. 1, pp. 125131, 2005.

[26] I. A. Rahman, P. Vejayakumaran, C. S. Sipaut et al., "Effect of anion electrolytes on the formation of silica nanoparticles via the sol-gel process," Ceramics International, vol. 32, no. 6, pp. 691-699, 2006.

[27] M. Jafarzadeh, I. A. Rahman, and C. S. Sipaut, "Synthesis of silica nanoparticles by modified sol-gel process: the effect of mixing modes of the reactants and drying techniques," Journal of Sol-Gel Science and Technology, vol. 50, no. 3, pp. 328-336, 2009.

[28] S. Kwon and G. L. Messing, "The effect of particle solubility on the strength of nanocrystalline agglomerates: boehmite," Nanostructured Materials, vol. 8, no. 4, pp. 399-418, 1997.

[29] I. A. Rahman, P. Vejayakumaran, C. S. Sipaut, J. Ismail, and C. K. Chee, "Effect of the drying techniques on the morphology of silica nanoparticles synthesized via sol-gel process," Ceramics International, vol. 34, no. 8, pp. 2059-2066, 2008.

[30] I. A. Rahman, P. Vejayakumaran, C. S. Sipaut, J. Ismail, and C. K. Chee, "Size-dependent physicochemical and optical properties of silica nanoparticles," Materials Chemistry and Physics, vol. 114, no. 1, pp. 328-332, 2009.

[31] S. K. Parida, S. Dash, S. Patel, and B. K. Mishra, "Adsorption of organic molecules on silica surface," Advances in Colloid and Interface Science, vol. 121, no. 1-3, pp. 77-110, 2006.

[32] V. M. Gun'ko, E. F. Voronin, L. V. Nosach et al., "Structural, textural and adsorption characteristics of nanosilica mechanochemically activated in different media," Journal of Colloid and Interface Science, vol. 355, no. 2, pp. 300-311, 2011.

[33] E. M. Rabinovich, J. B. Macchesney, D. W. Johnson et al., "Solgel preparation of transparent silica glass," Journal of NonCrystalline Solids, vol. 63, no. 1-2, pp. 155-161, 1984.

[34] O. Yong-Taeg, S. Fujino, and K. Morinaga, "Fabrication of transparent silica glass by powder sintering," Science and Technology of Advanced Materials, vol. 3, no. 4, pp. 297-301, 2002.

[35] N. Kurumoto, T. Yamada, and T. Uchino, "Enhanced blue photoluminescence from SiCl4-treated nanometer-sized silica particles," Journal of Non-Crystalline Solids, vol. 353, no. 5-7, pp. 684-686, 2007.

[36] T. Mohanty, N. C. Mishra, S. V. Bhat, P. K. Basu, and D. Kanjilal, "Dense electronic excitation induced defects in fused silica," Journal of Physics D, vol. 36, no. 24, pp. 3151-3155, 2003.

[37] M. C. Neves, T. Trindade, M. Peres et al., "Photoluminescence of zinc oxide supported on submicron silica particles," Materials Science and Engineering C, vol. 25, no. 5-8, pp. 654-657, 2005.

[38] L. Skuja, B. Güttler, D. Schiel, and A. R. Silin, "Infrared photoluminescence of preexisting or irradiation-induced interstitial oxygen molecules in glassy $\mathrm{SiO}_{2}$ and $\alpha$-quartz," Physical Review $B$, vol. 58, no. 21, pp. 14296-14304, 1998.

[39] M. Jafarzadeh, I. A. Rahman, and C. S. Sipaut, "Optical properties of amorphous organo-modified silica nanoparticles produced via co-condensation method," Ceramics International, vol. 36, no. 1, pp. 333-338, 2010. 
[40] Y. T. Chen, "Size effect on the photoluminescence shift in wide band-gap material: a case study of $\mathrm{SiO}_{2}$-nanoparticles," Tamkang Journal of Science and Engineering, vol. 5, no. 2, pp. 99-106, 2002.

[41] Y. D. Glinka, S. H. Lin, and Y. T. Chen, "The photoluminescence from hydrogen-related species in composites of $\mathrm{SiO}_{2}$ nanoparticles," Applied Physics Letters, vol. 75, no. 6, pp. 778$780,1999$.

[42] Y. D. Glinka, S. H. Lin, and Y. T. Chen, "Two-photon-excited luminescence and defect formation in $\mathrm{SiO}_{2}$ nanoparticles induced by 6.4-eV ArF laser light," Physical Review B, vol. 62, no. 7, pp. 4733-4743, 2000.

[43] Y. D. Glinka, S. H. Lin, and Y. T. Chen, "Time-resolved photoluminescence study of silica nanoparticles as compared to bulk type-III fused silica," Physical Review B, vol. 66, no. 3, pp. 035404-035413, 2002.

[44] A. N. Trukhin, L. N. Skuja, A. G. Boganov, and V. S. Rudenko, "The correlation of the $7.6 \mathrm{eV}$ optical absorption band in pure fused silicon dioxide with twofold-coordinated silicon," Journal of Non-Crystalline Solids, vol. 149, no. 1-2, pp. 96-101, 1992.

[45] H. Nishikawa, T. Shiroyama, R. Nakamura, Y. Ohki, K. Nagasawa, and Y. Hama, "Photoluminescence from defect centers in high-purity silica glasses observed under 7.9-eV excitation," Physical Review B, vol. 45, no. 2, pp. 586-591, 1992.

[46] S. Kang, S. I. Hong, C. R. Choe, M. Park, S. Rim, and J. Kim, "Preparation and characterization of epoxy composites filled with functionalized nanosilica particles obtained via sol-gel process," Polymer, vol. 42, no. 3, pp. 879-887, 2001.

[47] Y. Y. Yu, C. Y. Chen, and W. C. Chen, "Synthesis and characterization of organic-inorganic hybrid thin films from poly(acrylic) and monodispersed colloidal silica," Polymer, vol. 44, no. 3, pp. 593-601, 2002.

[48] H. Shu, X. Li, and Z. Zhang, "Surface modified nano-silica and its action on polymer," Progress in Chemistry, vol. 20, no. 10, pp. 1509-1514, 2008.

[49] K. N. Pham, D. Fullston, and K. S. Crentsil, "Surface modification for stability of nano-sized silica colloids," Journal of Colloid and Interface Science, vol. 315, no. 1, pp. 123-127, 2007.

[50] B. Wei, S. Song, and H. Cao, "Strengthening of basalt fibers with nano- $\mathrm{SiO}_{2}$-epoxy composite coating," Materials and Design, vol. 32, no. 8-9, pp. 4180-4186, 2011.

[51] M. Bailly, M. Kontopoulou, and K. El Mabrouk, "Effect of polymer/filler interactions on the structure and rheological properties of ethylene-octene copolymer/nanosilica composites," Polymer, vol. 51, no. 23, pp. 5506-5515, 2010.

[52] Y. Sun, Z. Zhang, and C. P. Wong, "Study on monodispersed nano-size silica by surface modification for underfill applications," Journal of Colloid and Interface Science, vol. 292, no. 2, pp. 436-444, 2005.

[53] P. Vejayakumaran, I. A. Rahman, C. S. Sipaut, J. Ismail, and C. K. Chee, "Structural and thermal characterizations of silica nanoparticles grafted with pendant maleimide and epoxide groups," Journal of Colloid and Interface Science, vol. 328, no. 1, pp. 81-91, 2008.

[54] F. Branda, B. Silvestri, G. Luciani, and A. Costantini, "The effect of mixing alkoxides on the Stöber particles size," Colloids and Surfaces A, vol. 299, no. 1-3, pp. 252-255, 2007.

[55] J. Kobler and T. Bein, "Porous thin films of functionalized mesoporous silica nanoparticles," ACS Nano, vol. 2, no. 11, pp. 2324-2330, 2008.

[56] T. M. Suzuki, T. Nakamura, K. Fukumoto, M. Yamamoto, Y. Akimoto, and K. Yano, "Direct synthesis of amino-func- tionalized monodispersed mesoporous silica spheres and their catalytic activity for nitroaldol condensation," Journal of Molecular Catalysis A, vol. 280, no. 1-2, pp. 224-232, 2008.

[57] I. A. Rahman, M. Jafarzadeh, and C. S. Sipaut, "Synthesis of organo-functionalized nanosilica via a co-condensation modification using $\gamma$-aminopropyltriethoxysilane (APTES)," Ceramics International, vol. 35, no. 5, pp. 1883-1888, 2009.

[58] S. Chen, A. Osaka, S. Hayakawa, K. Tsuru, E. Fujii, and K. Kawabata, "Novel one-pot sol-gel preparation of aminofunctionalized silica nanopartieles," Chemistry Letters, vol. 37, no. 11, pp. 1170-1171, 2008.

[59] Y. Naka, Y. Komori, and H. Yoshitake, "One-pot synthesis of organo-functionalized monodisperse silica particles in W/O microemulsion and the effect of functional groups on addition into polystyrene," Colloids and Surfaces A, vol. 361, no. 1-3, pp. 162-168, 2010.

[60] D. Kim, J. S. Lee, C. M. F. Barry, and J. L. Mead, "Effect of fill factor and validation of characterizing the degree of mixing in polymer nanocomposites," Polymer Engineering and Science, vol. 47, no. 12, pp. 2049-2056, 2007.

[61] J. M. Park, J. W. Kim, and D. J. Yoon, "Interfacial evaluation and microfailure mechanisms of single carbon fiber/ bismaleimide (BMI) composites by tensile and compressive fragmentation tests and acoustic emission," Composites Science and Technology, vol. 62, no. 6, pp. 743-756, 2002.

[62] J. Meng, X. Hu, F. Y. C. Boey, and L. Li, "Effect of layered nanoorganosilicate on the gel point rheology of bismaleimide/diallylbisphenol A resin,” Polymer, vol. 46, no. 8, pp. 2766-2776, 2005.

[63] G. Liang, X. Hu, and T. Lu, "Inorganic whiskers reinforced bismaleimide composites: part II the tribological behavior of BMI/potassium titanate composites," Journal of Materials Science, vol. 40, no. 7, pp. 1743-1748, 2005.

[64] Y. Z. Wan, Y. L. Wang, F. He, Y. Huang, and H. J. Jiang, "Mechanical performance of hybrid bismaleimide composites reinforced with three-dimensional braided carbon and Kevlar fabrics," Composites Part A, vol. 38, no. 2, pp. 495-504, 2007.

[65] H. Zhang, Z. Zhang, K. Friedrich, and C. Eger, "Property improvements of in situ epoxy nanocomposites with reduced interparticle distance at high nanosilica content," Acta Materialia, vol. 54, no. 7, pp. 1833-1842, 2006.

[66] J. G. I. Rodriguez, P. Carreira, A. G. Diez, D. Hui, R. Artiaga, and L. M. L. Marzan, "Nanofiller effect on the glass transition of a polyurethane," Journal of Thermal Analysis and Calorimetry, vol. 87, no. 1, pp. 45-47, 2007.

[67] X. F. Yao, D. Zhou, and H. Y. Yeh, "Macro/microscopic fracture characterizations of $\mathrm{SiO}_{2}$ /epoxy nanocomposites," Aerospace Science and Technology, vol. 12, no. 3, pp. 223-230, 2008.

[68] W. D. Liu, B. K. Zhu, J. Zhang, and Y. Y. Xu, "Preparation and dielectric properties of polyimide/silica nanocomposite films prepared from sol-gel and blending process," Polymers for Advanced Technologies, vol. 18, no. 7, pp. 522-528, 2007.

[69] J. Vega-Baudrit, V. Navarro-Bañón, P. Vázquez, and J. M. Martín-Martínez, "Addition of nanosilicas with different silanol content to thermoplastic polyurethane adhesives," International Journal of Adhesion and Adhesives, vol. 26, no. 5, pp. 378-387, 2006.

[70] S. C. Kwon, T. Adachi, W. Araki, and A. Yamaji, "Thermoviscoelastic properties of silica particulate-reinforced epoxy composites: considered in terms of the particle packing model," Acta Materialia, vol. 54, no. 12, pp. 3369-3374, 2006.

[71] M. Preghenella, A. Pegoretti, and C. Migliaresi, "Thermomechanical characterization of fumed silica-epoxy nanocomposites," Polymer, vol. 46, no. 26, pp. 12065-12072, 2005. 
[72] F. Bondioli, V. Cannillo, E. Fabbri, and M. Messori, "Epoxysilica nanocomposites: preparation, experimental characterization, and modeling," Journal of Applied Polymer Science, vol. 97, no. 6, pp. 2382-2386, 2005.

[73] G. Ragosta, M. Abbate, P. Musto, G. Scarinzi, and L. Mascia, "Epoxy-silica particulate nanocomposites: chemical interactions, reinforcement and fracture toughness," Polymer, vol. 46, no. 23, pp. 10506-10516, 2005.

[74] Y. L. Liu, C. Y. Hsu, W. L. Wei, and R. J. Jeng, "Preparation and thermal properties of epoxy-silica nanocomposites from nanoscale colloidal silica," Polymer, vol. 44, no. 18, pp. 51595167, 2003.

[75] Y. Y. Yu and W. C. Chen, "Transparent organic-inorganic hybrid thin films prepared from acrylic polymer and aqueous monodispersed colloidal silica," Materials Chemistry and Physics, vol. 82, no. 2, pp. 388-395, 2003.

[76] H. Wang, Y. Bai, S. Liu, J. Wu, and C. P. Wong, "Combined effects of silica filler and its interface in epoxy resin," Acta Materialia, vol. 50, no. 17, pp. 4369-4377, 2002.

[77] M. Q. Zhang, M. Z. Rong, S. L. Yu, B. Wetzel, and K. Friedrich, "Effect of particle surface treatment on the tribological performance of epoxy based nanocomposites," Wear, vol. 253, no. 9-10, pp. 1086-1093, 2002.

[78] Y. Chen, S. Zhou, H. Yang, G. Gu, and L. Wu, "Preparation and characterization of nanocomposite polyurethane," Journal of Colloid and Interface Science, vol. 279, no. 2, pp. 370-378, 2004.

[79] X. Gao, Y. Zhu, X. Zhao et al., "Synthesis and characterization of polyurethane/ $\mathrm{SiO}_{2}$ nanocomposites," Applied Surface Science, vol. 257, no. 10, pp. 4719-4724, 2011.

[80] A. Sargsyan, A. Tonoyan, S. Davtyan, and C. Schick, "The amount of immobilized polymer in $\mathrm{PMMA} \mathrm{SiO}_{2}$ nanocomposites determined from calorimetric data," European Polymer Journal, vol. 43, no. 8, pp. 3113-3127, 2007.

[81] S. P. Davtyan, A. A. Berlin, K. Shik, A. O. Tonoyan, and S. Z. Rogovina, "Polymer nanocomposites with a uniform distribution of nanoparticles in a polymer matrix synthesized by the frontal polymerization technique," Nanotechnologies in Russia, vol. 4, no. 7-8, pp. 489-498, 2009.

[82] P. Klonos, A. Panagopoulou, L. Bokobza, A. Kyritsis, V. Peoglos, and P. Pissis, "Comparative studies on effects of silica and titania nanoparticles on crystallization and complex segmental dynamics in poly(dimethylsiloxane)," Polymer, vol. 51, no. 23, pp. 5490-5499, 2010.

[83] D. Fragiadakis, L. Bokobza, and P. Pissis, "Dynamics near the filler surface in natural rubber-silica nanocomposites," Polymer, vol. 52, no. 14, pp. 3175-3182, 2011.

[84] P. Klonos, A. Panagopoulou, A. Kyritsis, L. Bokobza, and P. Pissis, "Dielectric studies of segmental dynamics in poly(dimethylsiloxane)/titania nanocomposites," Journal of NonCrystalline Solids, vol. 357, no. 2, pp. 610-614, 2011.

[85] H. Palza, R. Vergara, and P. Zapata, "Composites of polypropylene melt blended with synthesized silica nanoparticles," Composites Science and Technology, vol. 71, no. 4, pp. 535-540, 2011. 

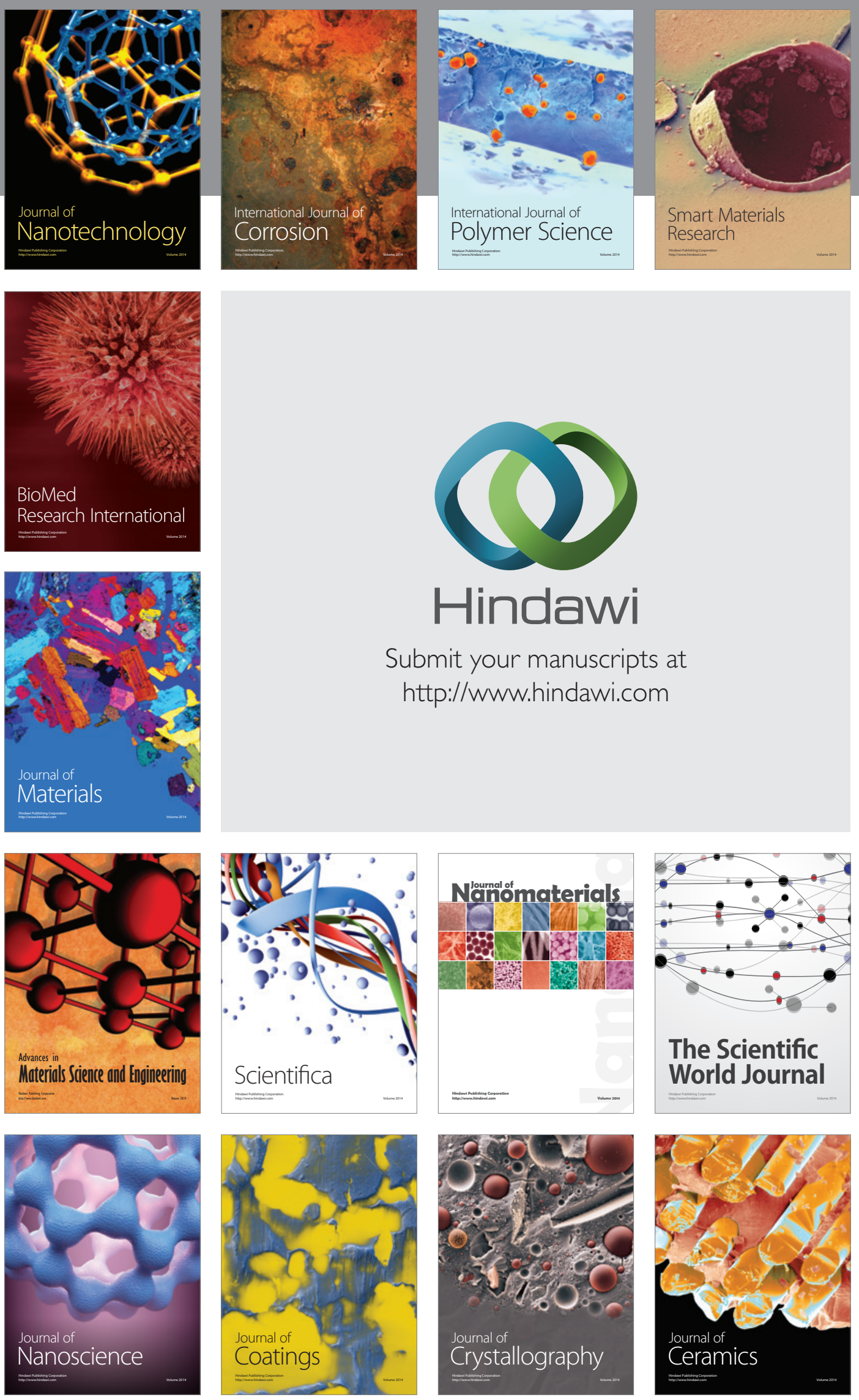

The Scientific World Journal

Submit your manuscripts at

http://www.hindawi.com

\section{World Journal}

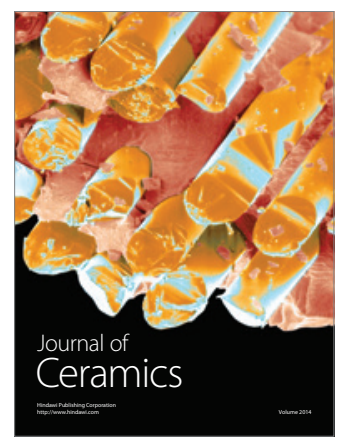

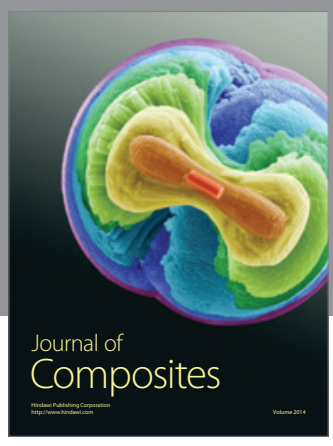
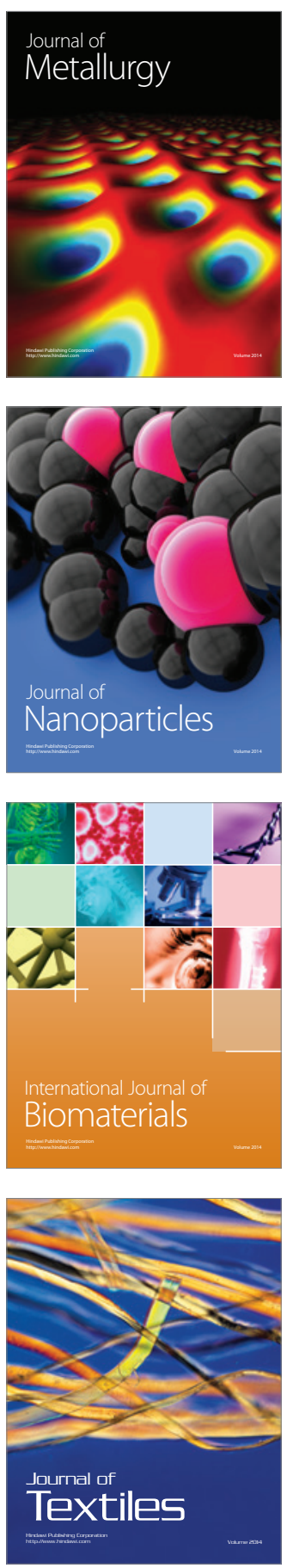